\title{
Synthesis of Carbon Nanotubes and Nanofibers on Silica and Cement Matrix Materials
}

\author{
Prasantha R. Mudimela, ${ }^{1}$ Larisa I. Nasibulina, ${ }^{1}$ Albert G. Nasibulin, ${ }^{1}$ Andrzej Cwirzen, ${ }^{2}$ \\ Markus Valkeapää, ${ }^{3}$ Karin Habermehl-Cwirzen, ${ }^{2}$ Jari E. M. Malm, ${ }^{3}$ Maarit J. Karppinen, ${ }^{3}$ \\ Vesa Penttala, ${ }^{2}$ Tatiana S. Koltsova, ${ }^{4}$ Oleg V. Tolochko, ${ }^{4}$ and Esko I. Kauppinen ${ }^{1,5}$

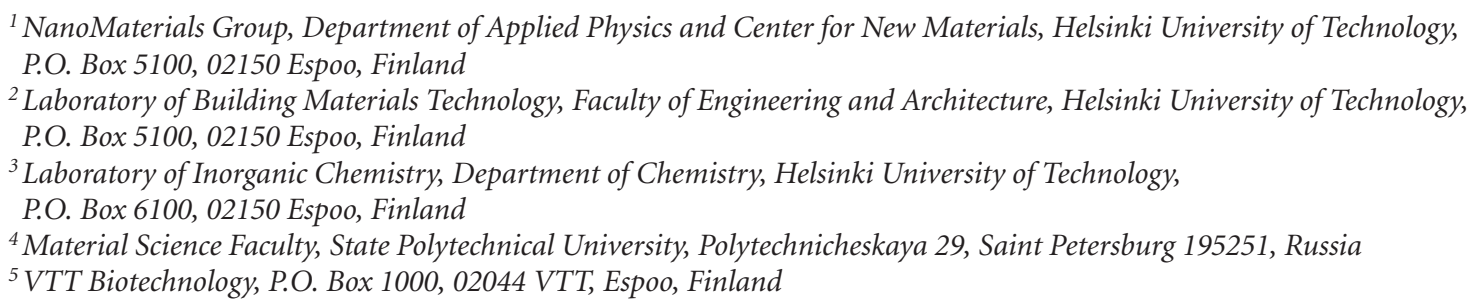

Correspondence should be addressed to

Albert G. Nasibulin, albert.nasibulin@hut.fi and Esko I. Kauppinen, esko.kauppinen@tkk.fi

Received 20 July 2009; Accepted 4 December 2009

Recommended by Alan K. T. Lau

\begin{abstract}
In order to create strong composite materials, a good dispersion of carbon nanotubes (CNTs) and nanofibers (CNFs) in a matrix material must be obtained. We proposed a simple method of growing the desirable carbon nanomaterial directly on the surface of matrix particles. CNTs and CNFs were synthesised on the surface of model object, silica fume particles impregnated by iron salt, and directly on pristine cement particles, naturally containing iron oxide. Acetylene was successfully utilised as a carbon source in the temperature range from 550 to $750^{\circ} \mathrm{C}$. 5-10 walled CNTs with diameters of $10-15 \mathrm{~nm}$ at $600^{\circ} \mathrm{C}$ and $12-20 \mathrm{~nm}$ at $750^{\circ} \mathrm{C}$ were synthesised on silica particles. In case of cement particles, mainly CNFs with a diameter of around $30 \mathrm{~nm}$ were grown. It was shown that high temperatures caused chemical and physical transformation of cement particles.
\end{abstract}

Copyright ( 2009 Prasantha R. Mudimela et al. This is an open access article distributed under the Creative Commons Attribution License, which permits unrestricted use, distribution, and reproduction in any medium, provided the original work is properly cited.

Carbon nanotubes (CNTs) and nanofibers (CNFs) have recently achieved significant scientific attention owing to their extraordinary and useful properties, such as exceptional tensile strength, elastic modulus and electrical and thermal conductivity $[1,2]$. Therefore, small additives of CNTs and CNFs to different materials can considerably improve their mechanical and electrical properties [3-5]. CNT/CNF reinforced cement composites are able to provide electromagnetic interference shielding [6] and also these composites capable of nondestructive flaw detection [7]. Utilization of CNTs/CNFs has been already occasionally investigated for applications in construction industry $[8,9]$ although the expected improvement has not been achieved, yet [10-12]. The biggest problem in the potential use of the carbon nanomaterials for making strong concrete arises when CNTs or CNFs are being introduced in the matrix material. Due to their high agglomeration/bundling addiction, the carbon nanomaterials cannot be easily and homogenously dispersed in a cement matrix by simple mixing procedure [12]. Usually multistep time consuming processes are required. Bulk amount of CNT/CNFs needs to be purified, functionalized, and only afterwards mixed with matrices. However, even this procedure does not lead to significant enhancement of the concrete mechanical properties due to poor bonding between the CNT/CNF and cement [12].

In this letter, we report a simple method to solve the problem of creating a good dispersion of CNTs and CNFs in a matrix. A desirable carbon nanomaterial can be 
simply grown on the surface of matrix particles. This also provides good bonding between the carbon nanomaterials and matrix. As a matrix material, we selected silica fume and cement particles. Silica particles with the size from $100 \mathrm{~nm}$ to $2 \mu \mathrm{m}$ were chosen as a model object for the comparative growth of CNTs/CNFs. In addition, silica is known to be used in construction industry to increase the strengths of concrete as a microfiller and a reactant in pozzolanic reaction during cement hydration [13]. Moreover, silica particles covered by CNTs/CNFs can be used to uniformly introduce the carbon nanostructures into concrete. As for another matrix, we selected cement, one of the most important construction materials. Cement consists of around 1-20 $\mu \mathrm{m}$ sized particles with broad size distribution and, importantly, naturally contains iron oxide. Thereby, it could be directly used as a catalyst and a support for the carbon nanomaterial synthesis. For this study, sulphate-resistant Portland type cement (CEM I $42.5 \mathrm{~N}$ ) with $3.4 \%$ (weight) $\mathrm{Fe}_{2} \mathrm{O}_{3}$ produced by Finnsementti Oy was used. Some of the other main cement components are $\mathrm{SiO}_{2}, \mathrm{MgO}$, and $\mathrm{Al}_{2} \mathrm{O}_{3}$, which are known to be good supporting materials for the CNT growth [14-16].

The growth of CNTs and CNFs was carried out by a conventional CVD method at atmospheric pressure. Acetylene and methane were examined as carbon sources. Cement particles were utilised without any additional pretreatment if not otherwise specified. For $\mathrm{SiO}_{2}$ impregnation by catalyst, $2 \mathrm{~g}$ of silica particles were mixed with $150 \mathrm{~mL}$ water based iron nitrate $\left(3.8 \times 10^{-3} \mathrm{M}\right)$ solution. Then, the solution was stirred for 1 hour and dried in an oven at $90^{\circ} \mathrm{C}$. In prior to use, the obtained powder was ground. For the CNT/CNF synthesis, either cement or impregnated silica powder were placed in a crucible boat, introduced into the quartz CVD tube (inner diameter of $12 \mathrm{~mm}$ ) reactor, and heated to the synthesis temperature in an argon atmosphere at the flow rate of $280 \mathrm{~cm}^{3} / \mathrm{min}$. In order to reduce iron oxide, a $280 \mathrm{~cm}^{3} / \mathrm{min}$ flow of hydrogen was introduced in the reactor for 5 minutes. After that, either acetylene or methane with the flow rate of $28 \mathrm{~cm}^{3} / \mathrm{min}$ were passed through the reactor for 20 minutes. Subsequently, after the synthesis stage, the carbon source and $\mathrm{H}_{2}$ were switched off and the reactor was cooled down to room temperature in the Ar flowing conditions.

Both silica and cement particles were completely covered by carbon nanomaterials when acetylene was used as the carbon source. On the surface of silica particles, mainly CNFs with the diameters varied from 30 to $50 \mathrm{~nm}$ were observed at $550^{\circ} \mathrm{C}$. Increasing temperature resulted in the growth of multiwalled CNTs with 5 to 10 walls as shown in Figure 1. The outer diameter of multiwalled CNTs varied from 10 to $15 \mathrm{~nm}$ at $600^{\circ} \mathrm{C}$ and from $12 \mathrm{~nm}$ to $20 \mathrm{~nm}$ at $750^{\circ} \mathrm{C}$. The maximum length of the CNTs was found to be $15 \mu \mathrm{m}$. In case of cement particles, mainly CNFs with the diameter of about $30 \mathrm{~nm}$ and average length of $3 \mu \mathrm{m}$ were grown at the same conditions applied for CNT growth on silica particles (Figure 2). The difference between the products synthesized on silica and cement particles gave us ground for a suggestion that the amount of catalyst was not sufficient in the cement particles. In order to examine this hypothesis, we impregnated cement particles with iron salt. For the impregnation, $0.4 \mathrm{~g}$ of cement was added to $56 \mathrm{~mL}$ ethanol-based iron nitrate $\left(3.8 \times 10^{-3} \mathrm{M}\right)$ solution. The solution was stirred for 1.5 hours and dried at ambient conditions. However, utilization of the impregnated cement particles slightly increased the yield of CNFs, but did not lead to the formation of CNTs. Most likely formation of different products on silica and cement particles is determined by different interaction of catalyst with substrate particles. Catalyst particles were found at the end of the CNTs, while the CNFs did not contain any catalyst at their tips. This gives us a base for a suggestion of tip mechanism of the CNT growth and root mechanism of the CNF formation. In this case, CNFs are likely attached to the cement substrate via the catalyst, which is apparently a part of the cement particles.

As cement was treated at high temperatures, it might undergo chemical alterations, which could make impossible to use this material for constructive purposes. In order to examine the possible changes, the cement particles were characterized by means of X-ray powder diffraction (XRD) analysis. The XRD data were collected on a Philips PW 1820 diffractometer by using $\mathrm{CuK} \alpha$ radiation. No major changes were found in the cement particles up to $700^{\circ} \mathrm{C}$, but new peaks corresponding to graphitized carbon appeared in the diffraction pattern (Figure 3). Also, gypsum phase vanished after the treatment at high temperatures. This can be explained by dehydration of gypsum $\mathrm{CaSO}_{4} \cdot 2 \mathrm{H}_{2} \mathrm{O}$ phase and formation of its anhydrate form [17]. Heat treatment of cement particles at $900^{\circ} \mathrm{C}$ led to the formation of free lime phase, $\mathrm{CaO}$, likely due to the decomposition of $\mathrm{Ca}_{3} \mathrm{SiO}_{5}$ to $\mathrm{Ca}_{2} \mathrm{SiO}_{4}[18]$. Thus, from the XRD data it can be concluded that the conditions of CNF and CNT synthesis did not significantly change the composition of cement particles. Therefore, the produced carbon nanomaterials would be easily homogenously dispersed in the concrete and mortar and could be intermingled with the products during cement hydration process [19].

Gypsum is usually added and mixed with clinker at the final stage of cement production and used mainly as an inhibitor for cement hydration process. For industrial applications, instead of cement, clinker particles should be used. This will firstly make the process of CNT/CNF-cement composite manufacturing cheaper, and secondly it will avoid chemical changes in the cement material. In order to confirm the possibility of using clinker as a catalyst and a support, we have carried out similar investigations with acetylene. We could not find a significant difference in products synthesized on cement and clinker.

It is worth noting that the described procedure for the synthesis of carbon nanomaterials did not allow us to produce $\mathrm{CNTs}$ and CNFs on cement particles using $\mathrm{CH}_{4}$ as a carbon source. This can be explained by the need of high temperatures $\left(850-950^{\circ} \mathrm{C}\right)$ for $\mathrm{CH}_{4}$ decomposition. At these temperatures cement particles change their crystal structure as was found by XRD investigations (Figure 3). On-line Fourier-Transform Infrared (FT-IR) measurements of the outlet gas phase composition revealed relatively high emission of $\mathrm{CO}_{2}$ and $\mathrm{H}_{2} \mathrm{O}$ in inert $\mathrm{Ar}$ atmosphere 


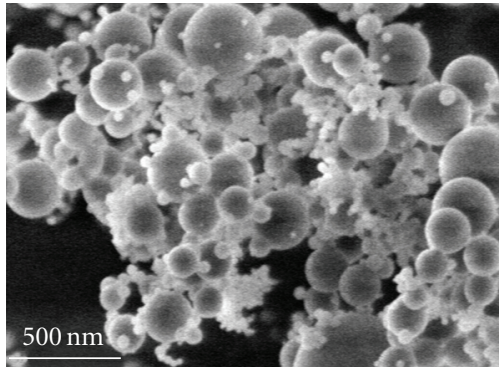

(a)

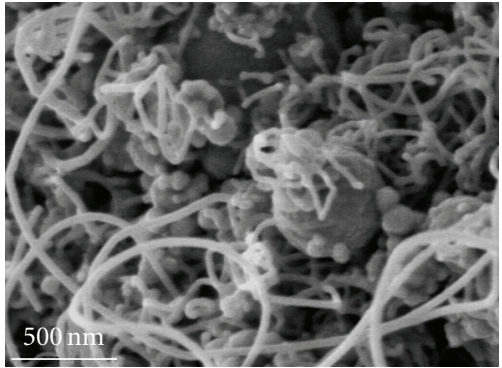

(b)

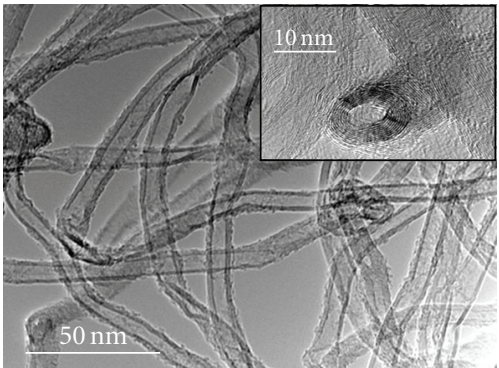

(c)

FIgURE 1: SEM images of (a) pristine silica particles and (b) silica particles treated at $600^{\circ} \mathrm{C}$ at the synthesis conditions, (c) TEM image of CNTs grown at $600^{\circ} \mathrm{C}$ on the surface of silica particles.

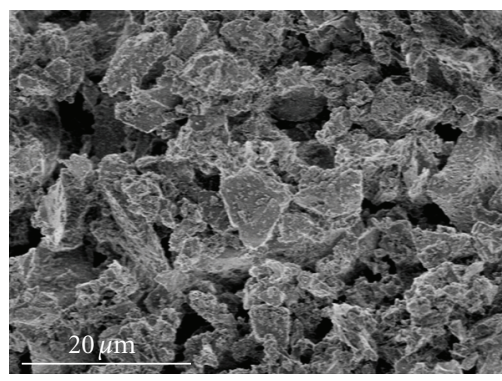

(a)

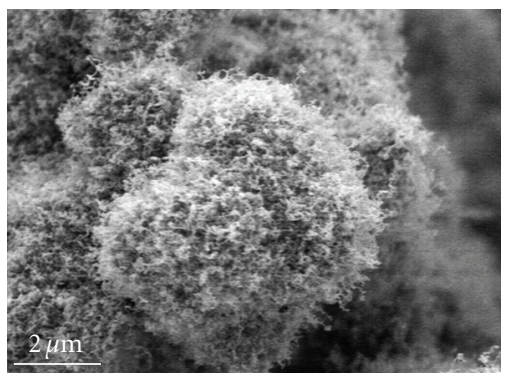

(b)

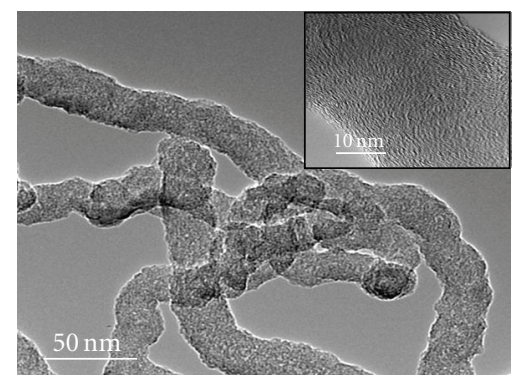

(c)

Figure 2: SEM images of (a) pristine cement particles and (b) cement treated at $650^{\circ} \mathrm{C}$ at the synthesis conditions, (c) TEM image of CNTs and $\mathrm{CNF}$ grown at $650^{\circ} \mathrm{C}$ on the surface of cement particles.

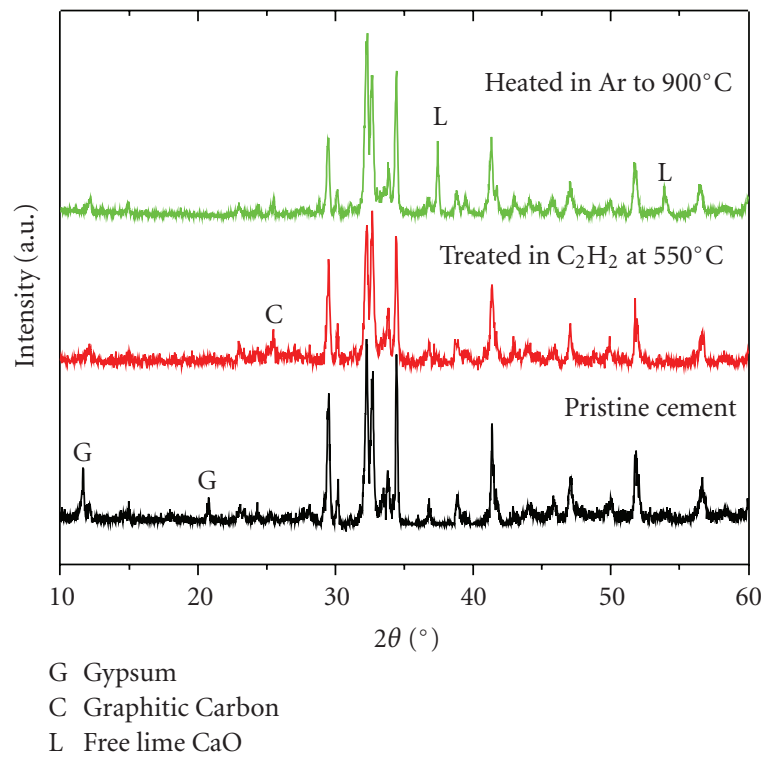

FIGURE 3: XRD patterns of pristine cement particles, the product after the synthesis at $550^{\circ} \mathrm{C}$ on the cement surface, and cement after the heat treatment at $900^{\circ} \mathrm{C}$ in $\mathrm{Ar}$ atmosphere.

during heating of the cement particles. These two gaseous compounds are known to behave as etching agents [20] and could completely suppress the growth of CNTs and CNFs on the surface of cement particles.

In conclusion, CNTs and CNFs were grown on the surface of model object, silica fume particles impregnated by iron salt, and directly on pristine cement particles using acetylene as a carbon source. The produced carbon nanomaterials are homogenously dispersed in the matrix materials, which solves the biggest problem of creating a good dispersion of CNTs and CNFs in a matrix and also provides good bonding between carbon and matrix materials. The experiments were carried out at the temperature range from 550 to $750^{\circ} \mathrm{C}$ and characterized by means of TEM, SEM, XRD, and FT-IR. It was found that at higher temperatures, cement particles underwent chemical and physical changes. These restrict the utilization of methane as a carbon source for the growth of carbon nanomaterials on the surface of cement particles.

\section{Acknowledgments}

This work was supported by the Academy of Finland (projects number 128445, 124283, and 128495) and by the Federal Agency for Science and Innovation. Prasantha R. Mudimela acknowledges Finnish National Graduate School in Nanoscience (NGS-NANO). 


\section{References}

[1] R. Saito, G. Dresselhaus, and M. S. Dresselhaus, Physical Properties of Carbon Nanotubes, Imperial College Press, London, UK, 1998.

[2] X. Zhang, Q. Li, T. G. Holesinger, et al., "Ultrastrong, stiff, and lightweight carbon-nanotube fibers," Advanced Materials, vol. 19, no. 23, pp. 4198-4201, 2007.

[3] J. E. Riggs, Z. Guo, D. L. Carroll, and Y.-P. Sun, "Strong luminescence of solubilized carbon nanotubes," Journal of the American Chemical Society, vol. 122, no. 24, pp. 5879-5880, 2000.

[4] K. P. De Jong and J. W. Geus, "Carbon nanofibers: catalytic synthesis and applications," Catalysis Reviews: Science and Engineering, vol. 42, no. 4, pp. 481-510, 2000.

[5] H. D. Wagner, O. Lourie, Y. Feldman, and R. Tenne, "Stressinduced fragmentation of multiwall carbon nanotubes in a polymer matrix," Applied Physics Letters, vol. 72, no. 2, pp. 188-190, 1998.

[6] X. Fu and D. D. L. Chung, "Submicron carbon filament cement-matrix composites for electromagnetic interference shielding," Cement and Concrete Research, vol. 26, no. 10, pp. 1467-1472, 1996.

[7] P.-W. Chen and D. D. L. Chung, "Carbon fiber reinforced concrete for smart structures capable of non-destructive flaw detection," Smart Materials and Structures, vol. 2, no. 1, pp. 22-30, 1993.

[8] G. Y. Li, P. M. Wang, and X. Zhao, "Mechanical behavior and microstructure of cement composites incorporating surfacetreated multi-walled carbon nanotubes," Carbon, vol. 43, no. 6, pp. 1239-1245, 2005.

[9] D. D. L. Chung, "Comparison of submicron-diameter carbon filaments and conventional carbon fibers as fillers in composite materials," Carbon, vol. 39, no. 8, pp. 1119-1125, 2001.

[10] P. Calvert, "Nanotube composites: a recipe for strength," Nature, vol. 399, no. 6733, pp. 210-211, 1999.

[11] W. Zhu, P. J. M. Bartos, and A. Porro, "Application of nanotechnology in construction summary of a state-of-the-art report," Materials and Structures, vol. 37, no. 273, pp. 649-658, 2004.

[12] J. M. Makar and J. J. Beaudoin, "Carbon nanotubes and their application in the construction industry," in Proceedings of the 1st International Symposium on Nanotechnology in Construction, pp. 331-341, Paisley, Scotland, 2004.

[13] J. K. Weng, B. W. Langen, and M. A. Ward, "Pozzolanic reaction in Portland cement, silica fume, and fly ash mixtures," Canadian Journal of Civil Engineering, vol. 24, no. 5, pp. 754760, 1997.

[14] K. Hernadi, A. Fonseca, J. B. Nagy, D. Bernaerts, J. Riga, and A. Lucas, "Catalytic synthesis and purification of carbon nanotubes," Synthetic Metals, vol. 77, no. 1-3, pp. 31-34, 1996.

[15] L. Qingwen, Y. Hao, C. Yan, Z. Jin, and L. Zhongfan, "A scalable CVD synthesis of high-purity single-walled carbon nanotubes with porous $\mathrm{MgO}$ as support material," Journal of Materials Chemistry, vol. 12, no. 4, pp. 1179-1183, 2002.

[16] J.-W. An and D.-S. Lim, "Synthesis and characterization of alumina/carbon nanotube composite powders," Journal of Ceramic Processing Research, vol. 3, no. 3, pp. 174-177, 2002.

[17] S. Sener, S. Bilgen, and G. Özbayoglu, "Effect of heat treatment on grindabilities of celestite and gypsum and separation of heated mixture by differential grinding," Minerals Engineering, vol. 17, no. 3, pp. 473-475, 2004.

[18] V. Sevcik and F. Skvara, "High-temperature properties of a binder based on gypsum-free Portland cement over the temperature range of 20 to $1200^{\circ}$ C," Ceramics-Silikáty, vol. 45, no. 4, pp. 151-157, 2001

[19] A. G. Nasibulin, S. D. Shandakov, L. I. Nasibulina, et al., "A novel cement-based hybrid material," New Journal of Physics, vol. 11, no. 10, Article ID 023013, 2009.

[20] A. G. Nasibulin, D. P. Brown, P. Queipo, D. Gonzalez, H. Jiang, and E. I. Kauppinen, "An essential role of $\mathrm{CO}_{2}$ and $\mathrm{H}_{2} \mathrm{O}$ during single-walled CNT synthesis from carbon monoxide," Chemical Physics Letters, vol. 417, no. 1-3, pp. 179-184, 2006. 

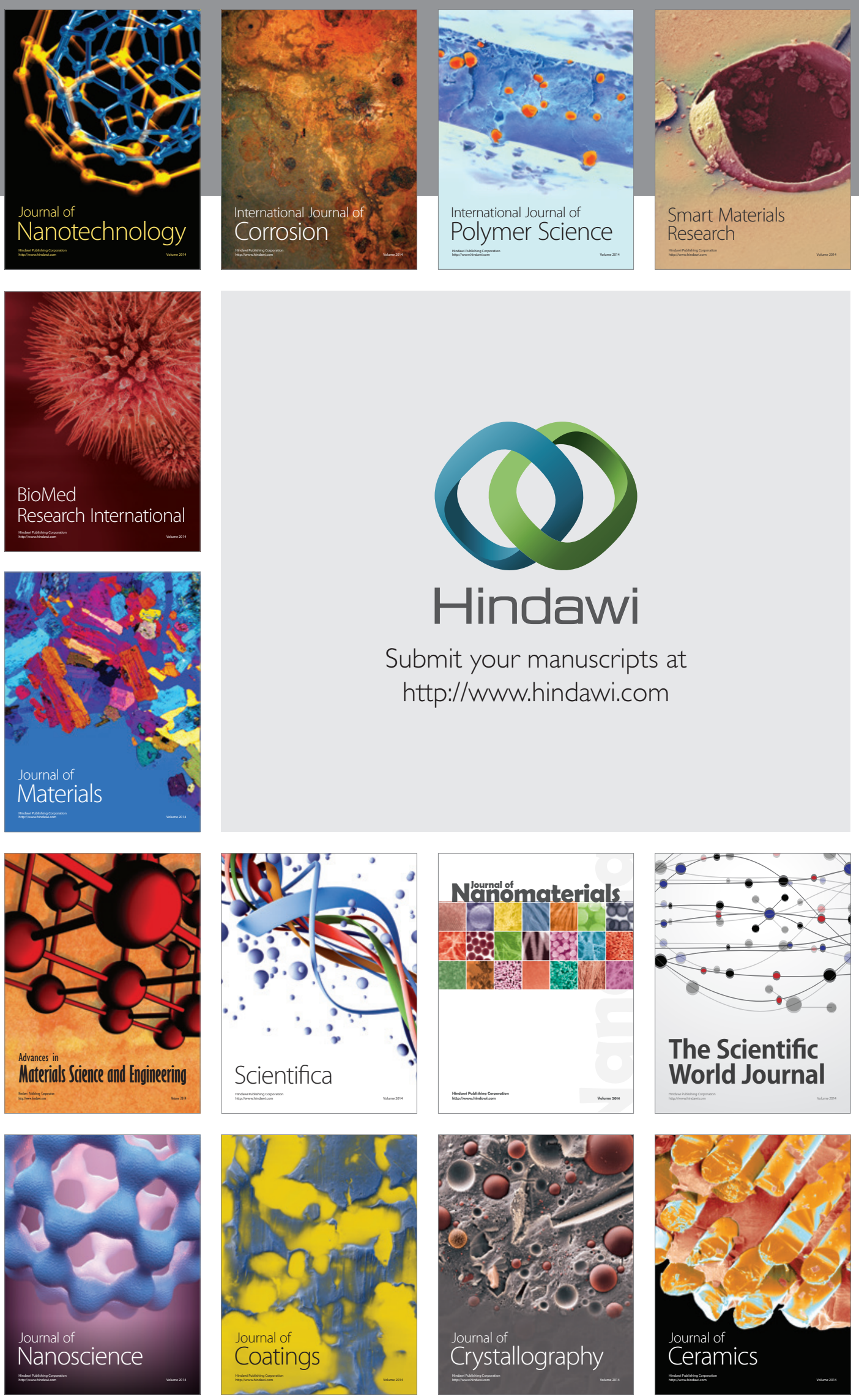

The Scientific World Journal

Submit your manuscripts at

http://www.hindawi.com

\section{World Journal}

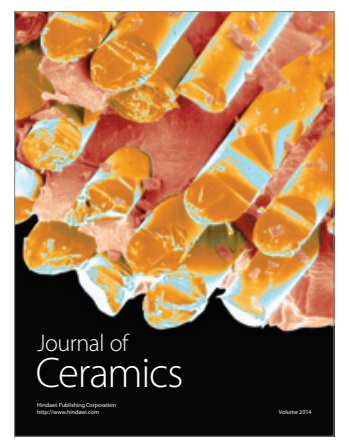

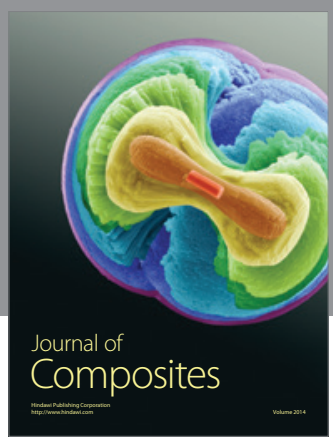
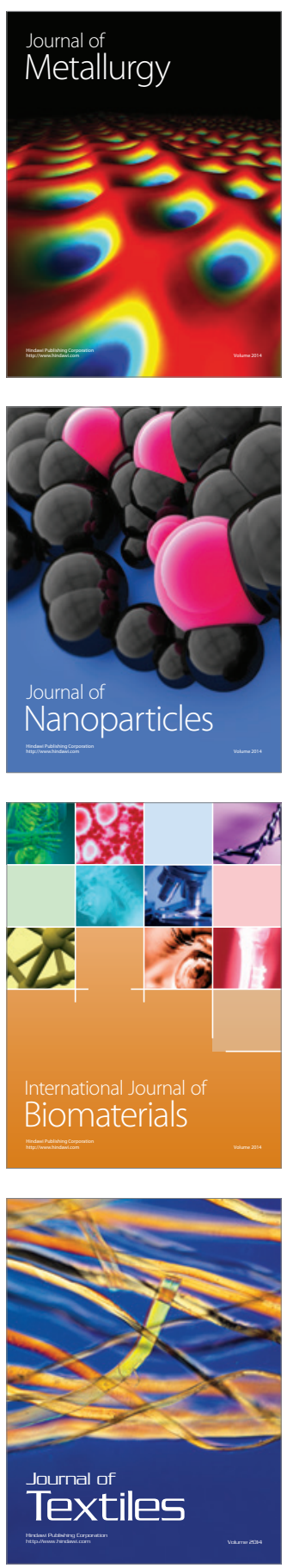